IPACK2005-73003

\title{
IMPACT OF CUBIC PIN FINNED SURFACE STRUCTURE GEOMETRY UPON SPRAY COOLING HEAT TRANSFER
}

\author{
Eric A. Silk ${ }^{\dagger}$ \\ Thermal Engineering Branch \\ NASA Goddard Space Flight Center \\ Greenbelt, MD 20771 \\ Tel:(301) 286-5534 Fax:(301) 286-1704 \\ Eric.A.Silk@nasa.gov
}

\author{
Jungho Kim \\ Mechanical Engineering Department \\ University of Maryland \\ College Park, MD 20742 \\ Tel:(301) 405-5437 Fax:(301) 314-9477 \\ kimjh@eng.umd.edu
}

\author{
Ken Kiger \\ Mechanical Engineering Department \\ University of Maryland \\ College Park, MD 20742 \\ Tel:(301) 405- 5245 Fax:(301) 314-9477 \\ kkiger@eng.umd.edu
}

\begin{abstract}
Experiments were conducted to study the effects of enhanced surface structures on heat flux using spray cooling. The surface enhancements consisted of cubic pin fins machined on the top surface of copper heater blocks. The structure height, pitch, and width were parametrically varied. Each copper block had a projected cross-sectional area of $2.0 \mathrm{~cm}^{2}$. Measurements were also obtained on a heater block with a flat surface for baseline comparison purposes. A $2 \times 2$ nozzle array was used with PF-5060 as the working fluid. Thermal performance data were obtained under nominally degassed (chamber pressure of $41.4 \mathrm{kPa}$ ) and gassy conditions (chamber with $\mathrm{N}_{2}$ gas at 100.7 $\mathrm{kPa}$ ) with a bulk fluid temperature of $20.5^{\circ} \mathrm{C}$. Results for both the degassed and gassy cases show that structure width and separation distance have a dominant effect upon the heat transfer for the size ranges used. Cubic pin fin height had little impact upon heat flux. The maximum critical heat flux (CHF) attained for any of the surfaces was $121 \mathrm{~W} / \mathrm{cm}^{2}$, giving an enhancement of $51 \%$ relative to the flat surface case under nominally degassed conditions. The gassy case had a maximum CHF of $149 \mathrm{~W} / \mathrm{cm}^{2}$, giving an enhancement of $38 \%$ relative to the flat surface case.
\end{abstract}

Keywords: Enhancement, Spray Cooling, Finned Surfaces, Dissolved Gas, Heat Transfer

\section{INTRODUCTION}

Many research efforts have been undertaken to gain a better understanding of the general phenomena and critical parameters associated with spray cooling heat transfer. A review of the literature shows that previous studies have parametrically examined the effect of secondary gas atomizers vs. pressure atomizers $[1,2]$, mass flux of ejected fluid $[3,4]$, spray velocity $[5,6]$, surface impact velocity $[5,7,8]$, surface roughness $[1,6,9,10]$, ejected fluid temperature, chamber environmental conditions, and spray footprint optimization on the effective heat flux across the heater surface [11]. Other topics researched to date include the effect of surfactant addition $[12,13]$, and secondary nucleation $[1,14,15]$.

This work is a continuation of the enhanced surface study by Silk et al. [16], with an emphasis on cubic pin fins as the basic geometric feature of the surface enhancement. The objective of the current work is to examine the effects of these geometries and their arrangement on heat flux when using spray cooling.

Most previous studies that have examined enhanced surfaces have done so primarily from the perspective of surface roughness. Sehmbey et al. [1] gives an overview of spray cooling and provides a comparison of its effectiveness when using liquid and secondary gas atomizers (air used as the secondary gas). Heat flux was measured and presented for both techniques. Both the heat flux and the convection coefficient were found to have comparable values for both atomizer types. The authors concluded that the most important parameters affecting heat transfer are the fluid properties, spray velocity and surface conditions. It was also found that the heat transfer coefficient increased with the use of smooth surfaces $\left(R_{a}<0.1\right.$ 
$\mu \mathrm{m})$ for gas atomized sprays, while the opposite trend was observed for liquid atomized sprays.

Pais et al. [10] studied the effects of surface roughness on heat transfer when using spray cooling. The surface roughness values studied were 22,14 and $0.3 \mu \mathrm{m}$. The sprayed surface was copper with a projected area of $1 \mathrm{~cm}^{2}$. An air-assist atomizing nozzle was used with deionized water as the working fluid. Tests were conducted at a nozzle height of $23 \mathrm{~mm}$. Tests were run up to $\mathrm{CHF}$ for all surface roughness values. It was found that the $0.3 \mu \mathrm{m}$ surface achieved the highest heat flux, with a peak heat flux of $1250 \mathrm{~W} / \mathrm{cm}^{2}$. Furthermore, the onset of nucleate boiling was experienced at lower superheat values. The authors attributed the heat transfer enhancement to early bubble departure from the surface and nucleate boiling. The authors also concluded that secondary nucleation has a primary role as a heat transfer mechanism only if the surface finish is smooth.

Much work has been performed on pool boiling using enhanced surfaces. Surface modifications previously investigated include the use of paints, porous structures, and structured surface geometries (macro, micro and submicronscale). Each of these techniques has been shown to enhance heat transfer given certain application constraints.

Honda et al. [17] investigated FC-72 boiling on silicon chips with micro-pin-fins, submicron-scale roughness and a combination surface utilizing both enhancements. The square pins had dimensions of $50 \times 50 \times 60 \mu \mathrm{m}^{3}$, while the submicronscale roughened surface had a Root Mean Square (RMS) roughness between 25 to $32 \mathrm{~nm}$. The effects of subcooling and dissolved gasses on heat flux were reported for each of these surfaces. The submicron-scale roughened surface displayed a higher heat transfer than the micro-pin-finned surface at low heat flux values. The opposite trend was observed at high heat flux. The combination surface displayed the highest heat transfer of all the surfaces with a CHF value of 1.8 to 2.3 times larger than the corresponding smooth surface case. CHF was found to vary linearly with subcooling for all chips.

Chien and Webb [18] investigated the effects of structured tunnel dimensions on nucleate boiling convection coefficients for heat fluxes ranging between 2 and $70 \mathrm{~kW} / \mathrm{m}^{2}$. Tests were performed on a $19.1 \mathrm{~mm}$ diameter horizontal tube using R-11 and R-123 as working fluids. Tunnel pitch, height, width, and base radius were the primary dimensions studied. The authors found that fins shorter than $0.9 \mathrm{~mm}$ experienced significant increases in the convection coefficient as the fin count increased from 1378 fins/m to 1575 fins $/ \mathrm{m}$. They also found that using straight fins promoted increased evaporation by retaining more liquid between neighboring fins. Increased fin height had little effect upon the convection coefficient. Fin pitch was also observed to have little effect.

The initial work by Silk et al. [16] showed that spray cooling of enhanced structure surfaces results in a corresponding heat flux enhancement. The present work investigates spray cooling heat flux as a function of cubic pin fin geometry and structure arrangement. Three surface parameters were varied monotonically between $1.0 \mathrm{~mm}$ and 2.0 $\mathrm{mm}$ in increments of $0.5 \mathrm{~mm}$. The parameters varied are the structure width $(\mathrm{X})$, structure separation distance $(\mathrm{L})$, and the structure height $(\mathrm{H})$. The geometries tested had wetted surface areas that varied from 1.4 to 3 times that of the baseline flat surface. It was found that CHF did not scale with the wetted surface area, indicating that fluid accumulation, drainage and convective effects on the interstitial areas are likely to be dominant factors controlling $\mathrm{CHF}$ enhancement.

$\begin{array}{ll}\text { NOMENCLATURE } \\ A & \text { Area } \\ H & \text { structure height } \\ L & \text { distance between successive structures } \\ \mathrm{P} & \text { Pressure } \\ R_{a} & \text { Surface Roughness } \\ T & \text { temperature } \\ T C & \text { thermocouple } \\ X & \text { structure feature dimension } \\ e & \text { error } \\ h & \text { convection coefficient } \\ k & \text { conductivity } \\ p & \text { pitch } \\ q^{\prime \prime} & \text { heat flux per unit area } \\ u & \text { uncertainty } \\ x & \text { thermocouple distance } \\ \Gamma & \text { weighted volume flux for concentric ring }\end{array}$

\section{SUBSCRIPTS}

$\begin{array}{ll}b & \text { base } \\ i & \text { concentric ring } \\ k & \text { conductivity } \\ C H F & \text { critical heat flux } \\ \min & \text { minimum } \\ n & \text { normalized } \\ q & \text { heat flux } \\ \text { surf } & \text { surface } \\ T & \text { temperature } \\ x & \text { thermocouple distance }\end{array}$

\section{TEST SETUP AND PROCEDURE}

The experiments were conducted using a closed fluid loop system. The test rig (schematic shown in Fig. 1) consists of an environmental test chamber, liquid pump, flow meter, microfilter and a condenser. Chamber temperature and pressure were measured via a T-type thermocouple and a pressure sensor.

Temperature and pressure sensors were also placed in the liquid line upstream of the nozzle for fluid and supply line temperature and pressure measurement.

Each of the test heaters were made of oxygen free copper with a uniform undercoat of $2.54 \mu \mathrm{m}$ nickel and $1.27 \mu \mathrm{m}$ topsurface coat of gold. Heat was supplied to the test article using a $500 \mathrm{~W}$ cartridge heater. The test article was placed within the interior of the chamber, but was separated from the excess liquid by an enclosure consisting of a polycarbonate housing 


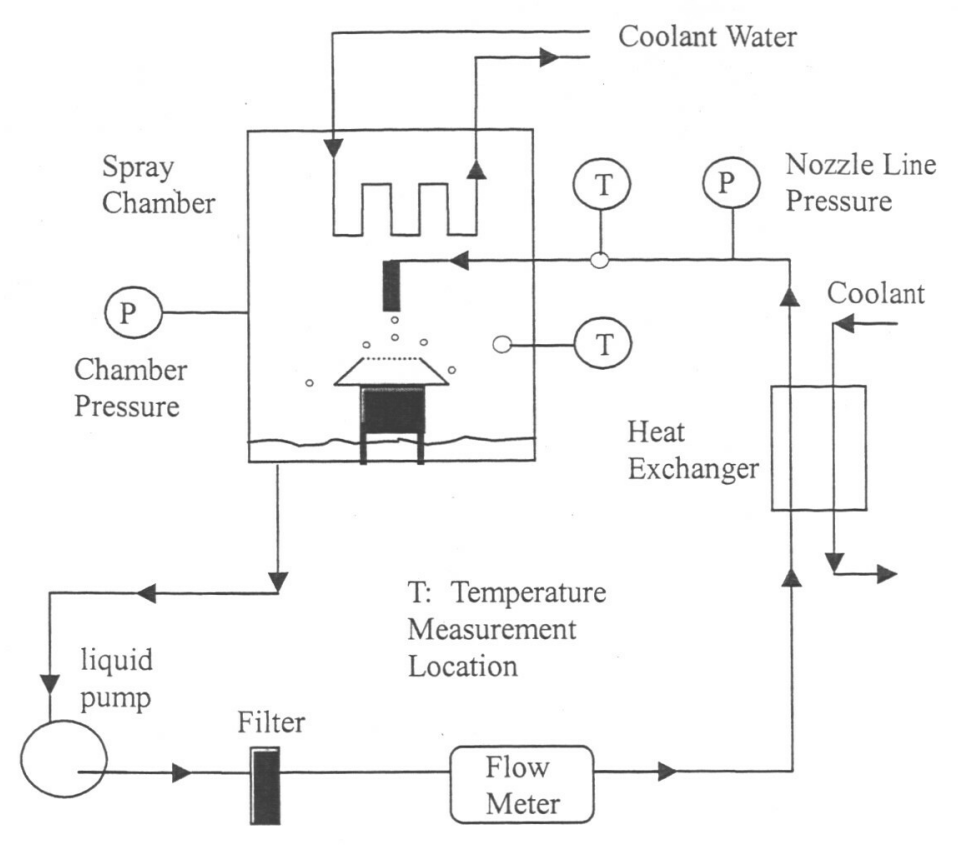

Fig. 1 Spray Cooling Test Rig Configuration

and an alumina bisque ceramic top flange. The upper section of the copper blocks was epoxied to the ceramic flange. Temperature measurements in the copper blocks were sampled via five T-type thermocouples mounted in the upper neck of each block (shown in Fig. 2). Assuming steady state 1-D conduction through the upper neck of the block, the heat flux was calculated using Fourier's Law. The reported heat flux was determined as the average values given from three pairs of thermocouples (TC1 \& TC3, TC2 \& TC4, and TC $3 \&$ TC5). Surface temperature was determined via linear extrapolation using TC1 and TC2.

Prior to each test, the spray chamber and fluid loop were charged with PF-5060. For the degassed case, a vacuum was repeatedly applied to the chamber until a pressure of $41.4 \mathrm{kPa}$ (470 ppm gas concentration) was reached. The chamber was allowed to attain equilibrium prior to conducting the tests. For the gassy case, the chamber was backfilled to $100.7 \mathrm{kPa}$ using $\mathrm{N}_{2}$ gas $(99.9 \%$ purity). The gas concentration for this case was $3821 \mathrm{ppm}$. All tests were run at constant chamber pressure, liquid flow rate $(200 \mathrm{ml} / \mathrm{min})$ and constant nozzle height above the heater surface. Heat was supplied to the cartridge heater in increments of $10 \mathrm{~W}$ using a programmable power supply. Steady state was achieved at each power level, and data acquired, before the heat load was increased for the next sample point. Dry-out was detected by a rapid increase in the surface temperature, upon which power to the cartridge heater was shut off.

A Parker Hannifin prototype spray nozzle was used for each of the tests. The nozzle consists of a $2 \times 2$ spray cone array. Prior to heat flux testing, the spray nozzle uniformity was measured using several stainless steel tubes of different inner

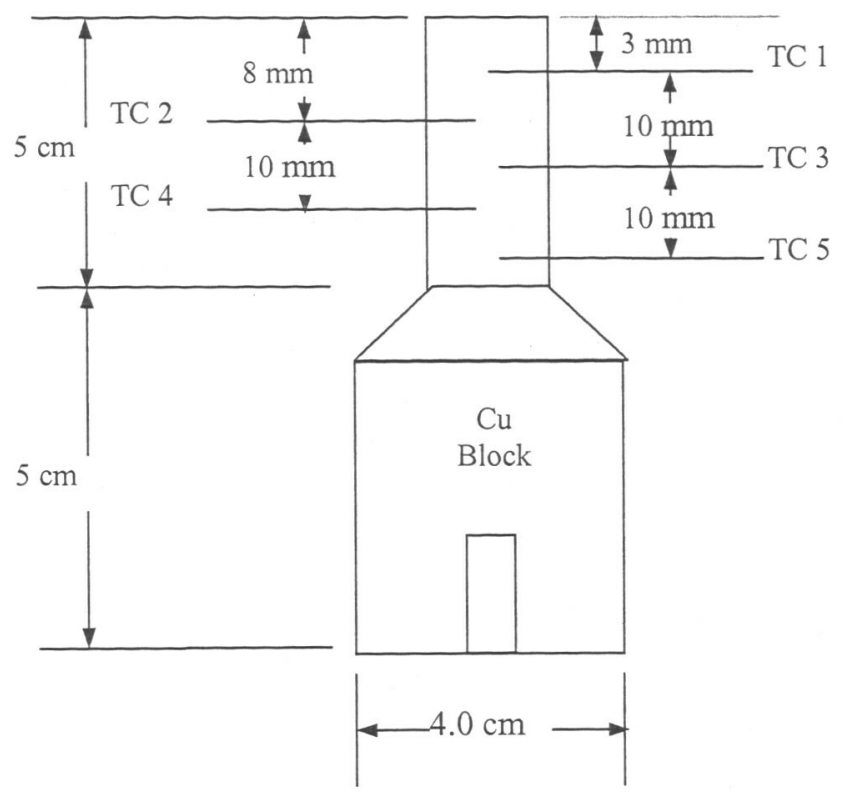

Fig. 2 Copper block schematic with TC locations (not to scale)

\begin{tabular}{|c|c|c|c|c|}
\hline Section & Area $\left(\mathrm{cm}^{2}\right)$ & Area $(\%)$ & $\begin{array}{c}\text { Vol. Flux } \\
\left(\mathrm{m}^{3} / \mathrm{m}^{2} \mathbf{s}\right)\end{array}$ & $\Gamma_{\mathrm{i}}$ \\
\hline $\mathrm{A}_{1}$ & 0.33 & 17.5 & 0.026 & 2.0 \\
\hline $\mathrm{A}_{2}$ & 0.38 & 20 & 0.024 & 1.8 \\
\hline $\mathrm{A}_{3}$ & 0.54 & 28.5 & 0.007 & 0.6 \\
\hline $\mathrm{A}_{4}$ & 0.64 & 34 & 0.005 & 0.4 \\
\hline
\end{tabular}

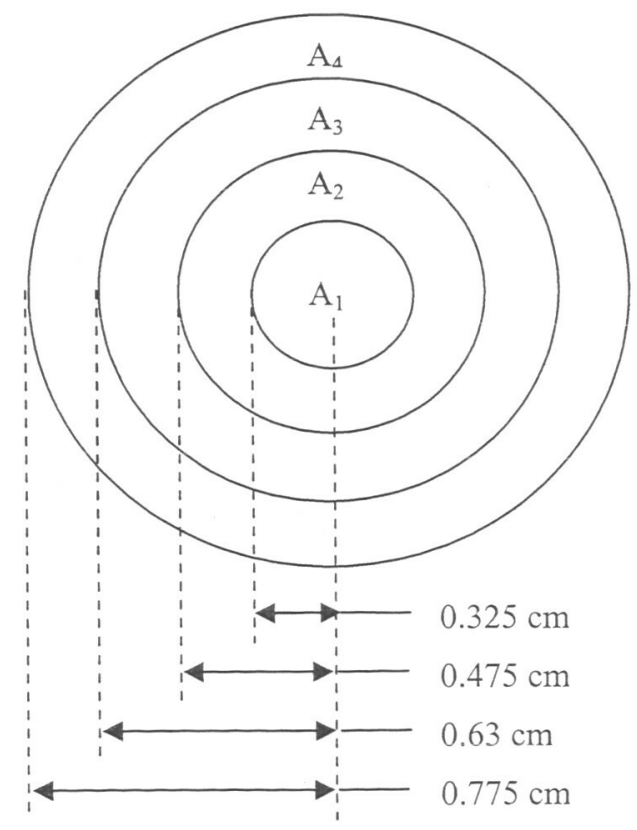

Fig. 3 Spray Uniformity Test Schematic (not to scale)

diameters, a graduated cylinder, and a stopwatch. The largest tube had an inner diameter approximately the same diameter as the heated surface. Size, local volume flux between concentric 


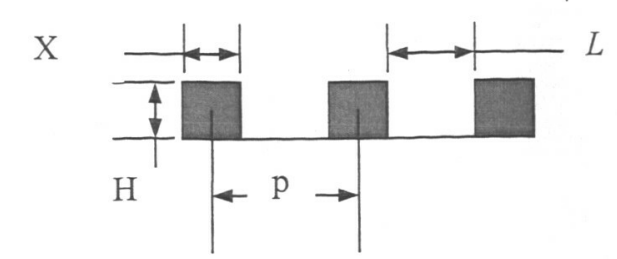

Cross Sectional View for Cubic Pin Fins

Fig. 4 Enhanced Surface Geometry Schematic

\begin{tabular}{|c|c|c|c|c|}
\hline $\begin{array}{c}\text { Cubic Pin Fin } \\
\text { Surface } \\
\text { Mnemonic }\end{array}$ & $\begin{array}{c}\mathbf{p} \\
(\mathrm{mm})\end{array}$ & $\begin{array}{c}\mathbf{X} \\
(\mathrm{mm})\end{array}$ & $\begin{array}{c}\mathbf{L} \\
(\mathrm{mm})\end{array}$ & $\begin{array}{c}\mathbf{H} \\
(\mathrm{mm})\end{array}$ \\
\hline $1 \mathrm{f}$ & 0 & 0 & 0 & 0 \\
\hline $1 \mathrm{c}$ & 2.0 & 1.0 & 1.0 & 1.0 \\
\hline $2 \mathrm{c}$ & 2.5 & 1.5 & 1.0 & 1.0 \\
\hline $3 \mathrm{c}$ & 3.0 & 2.0 & 1.0 & 1.0 \\
\hline $4 \mathrm{c}$ & 2.5 & 1.0 & 1.5 & 1.0 \\
\hline $5 \mathrm{c}$ & 3.0 & 1.0 & 2.0 & 1.0 \\
\hline $6 \mathrm{c}$ & 2.0 & 1.0 & 1.0 & 1.5 \\
\hline $7 \mathrm{c}$ & 2.0 & 1.0 & 1.0 & 2.0 \\
\hline
\end{tabular}

Table 1 Cubic Pin Fin Surface Geometry Summary

cylinders, and the local volume flux between concentric cylinders normalized by the volume flux averaged over the entire heater surface $(\Gamma)$ is shown in Fig. 3. A $\Gamma$ value of unity indicates that the local volume flux is identical to the average volume flux across the entire heater surface. The outer ring $\left(\mathrm{A}_{4}\right)$ can be seen to have $60 \%$ less volume flux than the average value. The volume flux is shown to gradually increase towards the center of the heater region. The center ring $\left(A_{1}\right)$, which encompasses only $17.5 \%$ of the heater area, has twice as much volume flux as the average flux for the entire area. Given the volume flux variation throughout the concentric rings, the spray may be effectively considered a non-uniform center biased spray. Spray characteristics were not investigated during this study.

The dimensions of the enhanced surfaces are shown on Fig. 4 and detailed in Table 1. The cubic pin fin block labeled if corresponds to the flat surface (no fins present). Photographs of the enhanced surfaces are shown in Fig. 5.

\section{MEASUREMENT UNCERTAINTY}

The primary quantity of interest for these experiments is the heat flux. The heat flux calculation has three sources of error. These are the conductivity, the thermocouple locations, and the error in the temperature measured. The conductivity value used was $389 \mathrm{~W} / \mathrm{m} \mathrm{K}$ with $1 \%$ error. From calibration tests in a temperature controlled bath using a mercury reference thermometer, the data acquisition unit used for the thermocouple measurements was estimated to have signal to temperature conversion accuracy of $\pm 0.1^{\circ} \mathrm{C}$. The error in the
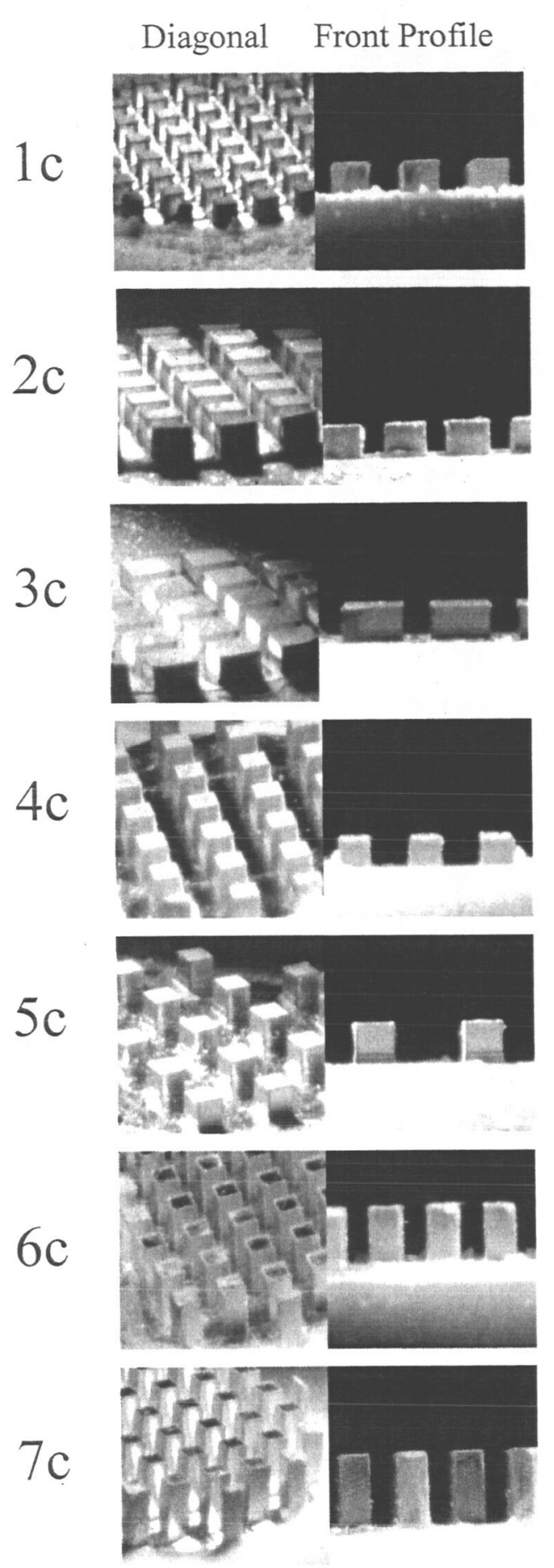

Fig. 5 Enhanced Surface CCD Images

thermocouple location was determined to be $\pm 0.56 \mathrm{~mm}$. Equation 1 was used to calculate the error for the heat flux values reported.

$$
u_{q}= \pm \sqrt{\left(\frac{\partial q}{\partial k} \cdot e_{k}\right)^{2}+\left(\frac{\partial q}{\partial T} \cdot e_{T}\right)^{2}+\left(\frac{\partial q}{\partial x} \cdot e_{x}\right)^{2}}
$$


The uncertainty in the heat flux was determined to be $3.5 \%$ at $80 \mathrm{~W} / \mathrm{cm}^{2}$. Pressure values recorded had an uncertainty of \pm 3 $\mathrm{kPa}$. Flow meter measurements were attributed an error of \pm 1 $\mathrm{ml} / \mathrm{min}$.

\section{DEGASSED CASE}

Heat flux as a function of the structure width $(\mathrm{X})$, separation distance $(\mathrm{L})$, and height $(\mathrm{H})$ for the nominally degassed case is shown respectively in Figs. 6,7 and 8. For the gassy case, the corresponding results are shown in Figs. 9, 10 and 11 , respectively. The calculated heat flux is based on the projected area of $2.0 \mathrm{~cm}^{2}$ for all cases, as opposed to the wetted surface area exposed to the fluid.

In the degassed case, the heat transfer variation for all surfaces is linear in the low heat flux regime, which is indicative of single phase convection. Mulitphase effects become pronounced (denoted by the increase in slope of the heat flux curves) around $\mathrm{T}_{\text {surf }} \approx 52^{\circ} \mathrm{C}$ for the $\mathrm{X}$ and $\mathrm{L}$ variations (Figs. 6 and 7). In both cases, 1c attained the highest heat flux (117 $\mathrm{W} / \mathrm{cm}^{2}$ ). The heat flux decreased as both $\mathrm{X}$ and $\mathrm{L}$ were increased beyond the initial values for case $1 \mathrm{c}$. For the $\mathrm{X}$ variation study (Fig. 6), case $3 \mathrm{c}$ showed a departure from the $1 \mathrm{c}$ case while still within the single phase regime. Case $2 \mathrm{c}$ did not show departure from $1 \mathrm{c}$ until transitioning to the high heat flux regime $\left(T_{\text {surf }} \approx 60^{\circ} \mathrm{C}\right)$. CHF for cases $3 \mathrm{c}$ and $4 \mathrm{c}$ were 103 $\mathrm{W} / \mathrm{cm}^{2}$ and $104 \mathrm{~W} / \mathrm{cm}^{2}$ respectively. Thus there was little change between the two.

The L variation study (Fig. 7) did not show separation between any of the cases until transition to the intermediate heat flux regime $\left(\mathrm{T}_{\text {surf }} \approx 52^{\circ} \mathrm{C}\right)$. Above this temperature, case $1 \mathrm{c}$ began to exhibit distinctly higher heat fluxes than cases $4 \mathrm{c}$

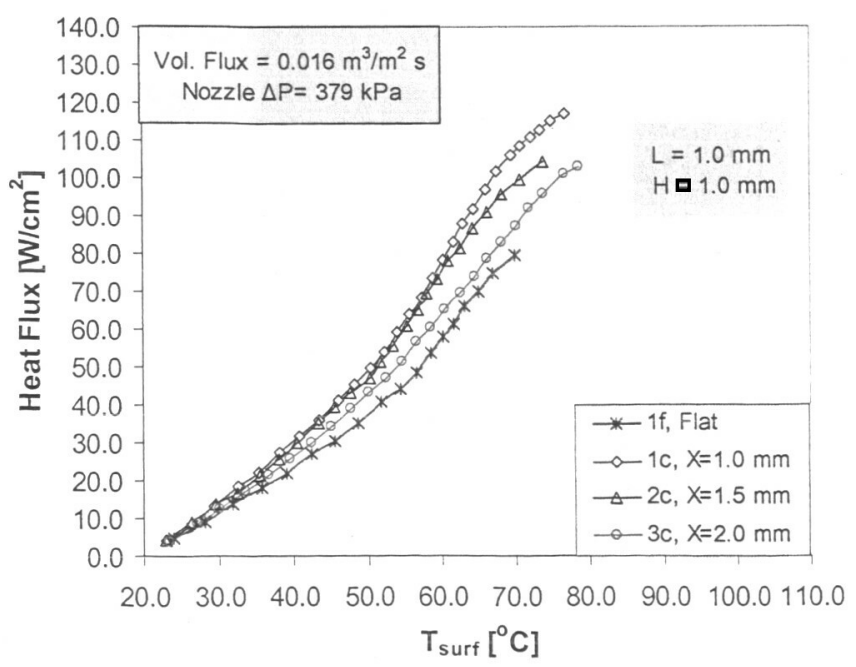

Fig. 6 Heat Flux as a function of Surface Temperature using variable structure size $(\mathrm{X})$ for degassed case

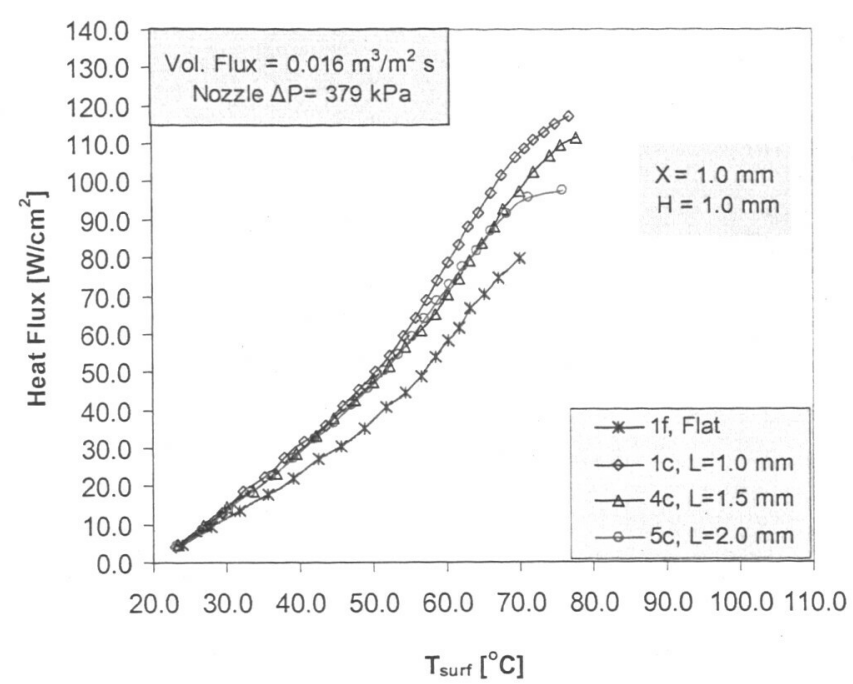

Fig. 7 Heat Flux as a function of Surface Temperature using variable structure separation distance (L) for degassed case

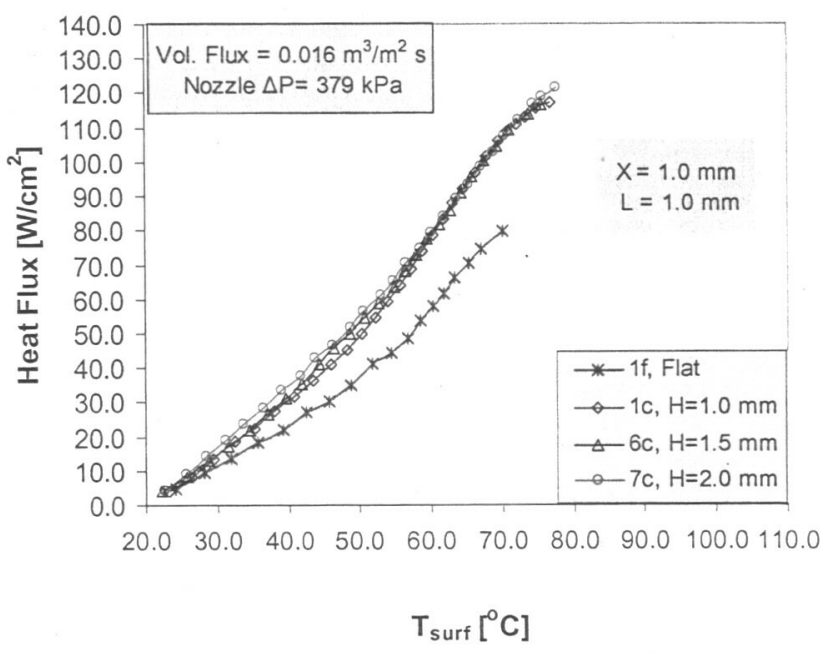

Fig. 8 Heat Flux as a function of Surface Temperature using variable Height $(\mathrm{H})$ for degassed case

and $5 \mathrm{c}$. Cases $4 \mathrm{c}$ and $5 \mathrm{c}$ agreed well until transition to the high heat flux regime $\left(T_{\text {surf }} \approx 68^{\circ} \mathrm{C}\right)$. CHF for cases $1 \mathrm{c}$ and $4 \mathrm{c}$ had a difference of only $5 \mathrm{~W} / \mathrm{cm}^{2}$ (see Table 2 for numerical values). Case $5 \mathrm{c}$ had the minimum CHF value $\left(97 \mathrm{~W} / \mathrm{cm}^{2}\right)$ for both this variation and all of the enhanced surfaces tested.

From the tests conducted to study the effects of $\mathrm{H}$ variation (Fig. 8), it can be seen that there was very little difference among the three cases for the range of values tested. Similar to the other cases, the onset of multiphase effects occurs at approximately $\mathrm{T}_{\text {surf }} \approx 55^{\circ} \mathrm{C}$. For the low heat flux regime, case $7 \mathrm{c}$ showed slightly higher values. Beyond the multiphase transition point, all values agreed within the experimental 


\begin{tabular}{|c|c|c|c|c|}
\hline $\begin{array}{c}\text { Cubic } \\
\text { Pin Fin } \\
\text { Surface }\end{array}$ & $\begin{array}{c}\mathbf{A}_{\mathbf{s}} \\
\left(\mathrm{cm}^{2}\right)\end{array}$ & $\begin{array}{c}\mathbf{A}_{b} \\
\left(\mathrm{~cm}^{2}\right)\end{array}$ & $\begin{array}{c}\mathbf{q}^{\prime \prime} \mathrm{cHF}^{2} \\
\left(\mathbf{W} / \mathrm{cm}^{2}\right)\end{array}$ & $\begin{array}{c}\mathbf{T}_{\max } \\
\left({ }^{\circ} \mathbf{C}\right)\end{array}$ \\
\hline 1f & 2.0 & 2.0 & 80 & 70.0 \\
\hline 1c & 4.0 & 1.5 & 117 & 76.8 \\
\hline 2c & 3.9 & 1.3 & 104 & 73.9 \\
\hline $3 \mathrm{c}$ & 3.8 & 1.1 & 103 & 78.8 \\
\hline $4 \mathrm{c}$ & 3.3 & 1.7 & 112 & 77.9 \\
\hline $5 \mathrm{c}$ & 2.9 & 1.8 & 97 & 75.9 \\
\hline $6 \mathrm{c}$ & 5.0 & 1.5 & 116 & 75.5 \\
\hline $7 \mathrm{c}$ & 6.0 & 1.5 & 121 & 77.7 \\
\hline
\end{tabular}

Table 2 Summary of Cubic Pin Fin Surface degassed case data

uncertainty. The maximum surface temperature occurred within a range of $2^{\circ} \mathrm{C}$ for each case, with $\mathrm{CHF}$ spanning a range of 5 $\mathrm{W} / \mathrm{cm}^{2}$ (shown in Table 2). Case $7 \mathrm{c}$ had the maximum CHF $\left(121 \mathrm{~W} / \mathrm{cm}^{2}\right)$. The fact that the height variation had little impact upon the heat flux implied that heat transfer predominantly occurred within $1.0 \mathrm{~mm}$ from the base surface.

Table 2 summarizes the total wetted surface area, CHF, and corresponding surface temperature for each of the blocks tested for the degassed case. The base area $\left(A_{b}\right)$ is defined as the surface area at the base excluding the area immediately covered by the enhanced surface structures.

\section{GASSY CASE}

The $\mathrm{X}$ variation for the gassy case (Fig. 9) showed similar enhancement behavior to the nominally degassed case. At transition to the multiphase region $\left(\mathrm{T}_{\text {surf }} \approx 65^{\circ} \mathrm{C}\right)$, cases $1 \mathrm{c}$ and $2 \mathrm{c}$ begin to coincide. Divergence from one another occurs later as $\mathrm{CHF}$ is approached. As in the nominally degassed $\mathrm{X}$ variation (Fig. 6), 3c performed noticeably lower than the other two $(1 \mathrm{c}$ and $2 \mathrm{c}$ ) for all surface temperatures. CHF for case $3 \mathrm{c}$ was $132 \mathrm{~W} / \mathrm{cm}^{2}$, compared to $145 \mathrm{~W} / \mathrm{cm}^{2}$ for case $1 \mathrm{c}$ (shown in Table 3).

The $\mathrm{L}$ variation (Fig. 10) cases $(4 \mathrm{c}$ and $5 \mathrm{c}$ ) agreed well throughout the single phase $\left(\mathrm{T}_{\text {surf }} \leq 65^{\circ} \mathrm{C}\right)$ and intermediate heat flux regimes $\left(65^{\circ} \mathrm{C} \leq \mathrm{T}_{\text {surf }} \leq 80^{\circ} \mathrm{C}\right)$. Case $1 \mathrm{c}$ held marginally higher heat fluxes in both of these regimes. Upon entering into the high heat flux regime, case $5 \mathrm{c}$ attained $\mathrm{CHF}\left(123 \mathrm{~W} / \mathrm{cm}^{2}\right)$ at a lower surface temperature than cases $4 \mathrm{c}$ and $1 \mathrm{c}$. This also occurred in the nominally degassed study. Case 1c had the highest CHF value $\left(145 \mathrm{~W} / \mathrm{cm}^{2}\right)$ with case $4 \mathrm{c}$ virtually the same $\left(142 \mathrm{~W} / \mathrm{cm}^{2}\right)$.

The $\mathrm{H}$ variation (Fig. 11) showed good agreement for cases $1 \mathrm{c}$ and $6 \mathrm{c}$, with $7 \mathrm{c}$ slightly higher throughout the surface temperature domain. This was similar to the behavior observed for the degassed case (Fig. 8). CHF for case $7 \mathrm{c}\left(149 \mathrm{~W} / \mathrm{cm}^{2}\right)$ had a difference of only $4 \mathrm{~W} / \mathrm{cm}^{2}$ from CHF for cases $1 \mathrm{c}(145$ $\left.\mathrm{W} / \mathrm{cm}^{2}\right)$ and $6 \mathrm{c}\left(145 \mathrm{~W} / \mathrm{cm}^{2}\right)$. Table 3 summarizes the total wetted surface area, $\mathrm{CHF}$, and corresponding surface temperature for each of the blocks tested for the gassy case.

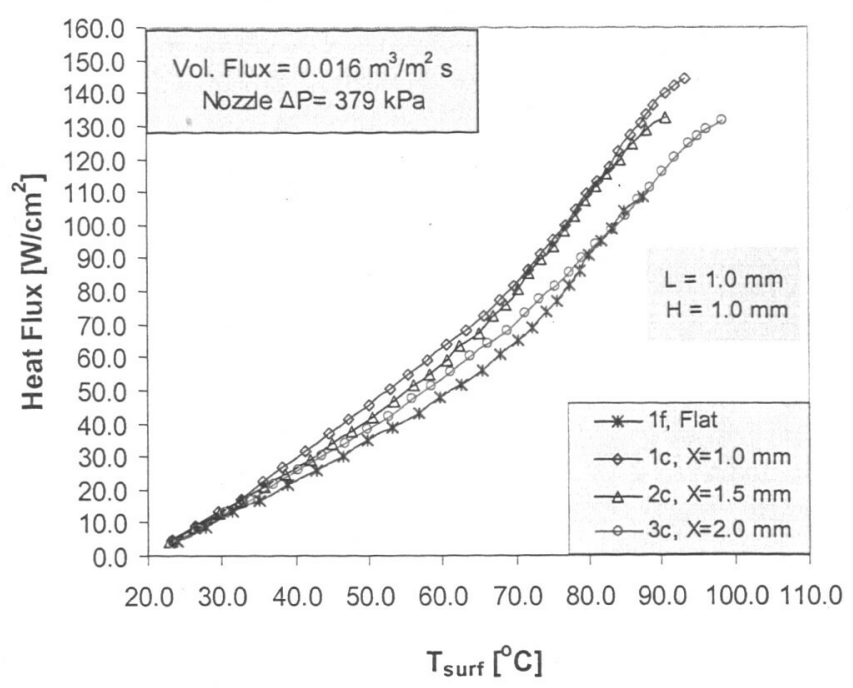

Fig. 9 Heat Flux as a function of Surface Temperature using variable structure size $(\mathrm{X})$ for gassy case

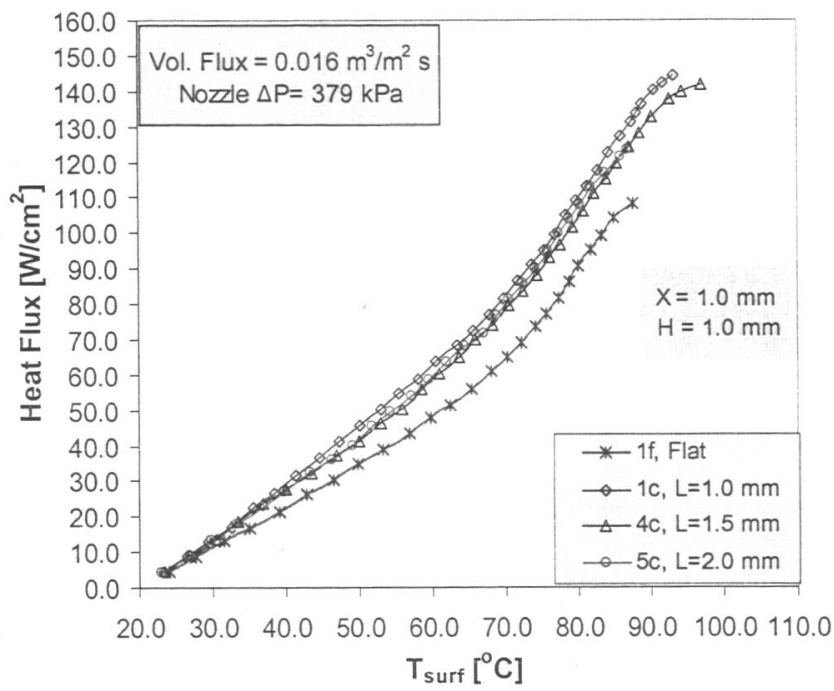

Fig. 10 Heat Flux as a function of Surface Temperature using variable structure separation distance (L) for gassy case

The initial investigation by Silk et al. [16] concluded that the heat flux enhancement observed when using surface structures such as straight fins and cubic pin fins was highly dependent upon fluid management on the heater surface. Furthermore, it was determined that $\mathrm{CHF}$ did not scale with the total wetted surface area for dissimilar geometries. A more appropriate comparison can be made by comparing similar surface geometries with different surface areas. Under this assumption there are two areas of interest. The first would be the total surface area $\left(A_{s}\right)$. This is pertinent from the perspective of total heat exchange. The second is the base area of the channel $\left(A_{b}\right)$. During the tests the fluid was observed to flood the channels. 


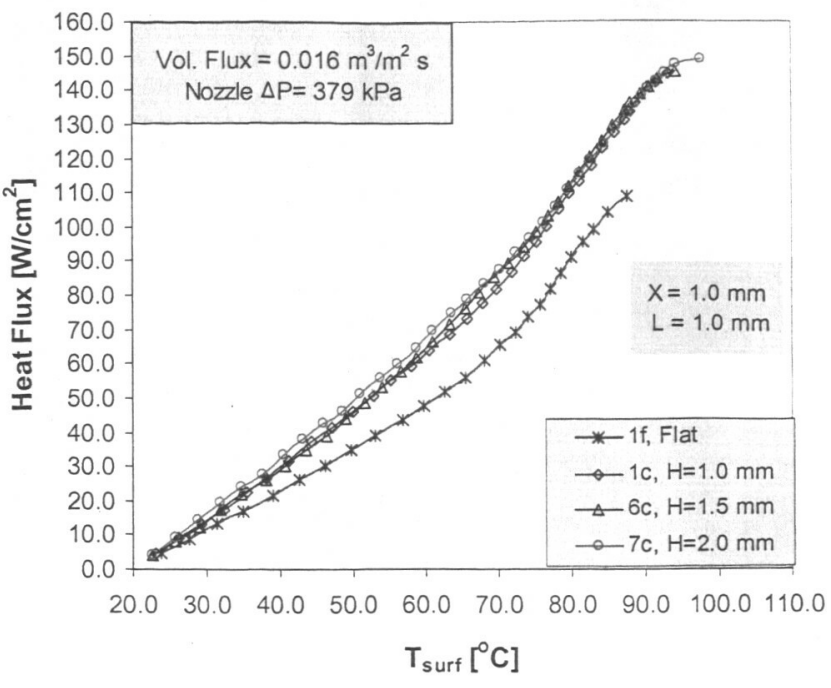

Fig. 11 Heat Flux as a function of Surface Temperature using variable Height $(\mathrm{H})$ for gassy case

\begin{tabular}{|c|c|c|c|c|}
\hline $\begin{array}{c}\text { Cubic } \\
\text { Pin Fin } \\
\text { Surface }\end{array}$ & $\begin{array}{c}\mathbf{A}_{\mathbf{s}} \\
\left(\mathbf{c m}^{2}\right)\end{array}$ & $\begin{array}{c}\mathbf{A}_{\mathbf{b}} \\
\left(\mathrm{cm}^{2}\right)\end{array}$ & $\begin{array}{c}\mathbf{q}^{\prime \prime} \mathbf{c H F}^{2} \\
\left(\mathbf{W} / \mathbf{c m}^{2}\right)\end{array}$ & $\begin{array}{c}\mathbf{T}_{\max } \\
\left({ }^{\circ} \mathbf{C}\right)\end{array}$ \\
\hline $1 f$ & 2.0 & 2.0 & 108 & 87.5 \\
\hline $1 \mathrm{c}$ & 4.0 & 1.5 & 145 & 93.3 \\
\hline $2 \mathrm{c}$ & 3.9 & 1.3 & 132 & 90.7 \\
\hline $3 \mathrm{c}$ & 3.8 & 1.1 & 132 & 98.3 \\
\hline $4 \mathrm{c}$ & 3.3 & 1.7 & 142 & 97 \\
\hline $5 \mathrm{c}$ & 2.9 & 1.8 & 123 & 86.8 \\
\hline $6 \mathrm{c}$ & 5.0 & 1.5 & 145 & 94.3 \\
\hline $7 \mathrm{C}$ & 6.0 & 1.5 & 149 & 97.6 \\
\hline
\end{tabular}

Table 3 Summary of Cubic Pin Fin Surface gassy case data

Thus $A_{b}$ (which will impact the channel fluid volume) and its relationship to the heat flux is worth examining.

A review of Tables 2 and 3 show that the heat fluxes for the surveyed structures do not scale comprehensively with either $A_{s}$ or $A_{b}$ in the degassed or gassy cases. When the $\mathrm{X}$ and $\mathrm{L}$ parameters are individually varied, increases in $A_{s}$ generally correspond to increases in $\mathrm{CHF}$ for both the degassed and gassy cases. For both the degassed and gassy $\mathrm{H}$ variation studies (Figs. 8 and 11), the heat flux showed very little variation ( $\leq$ $4 \%$ ) for the heights tested throughout the surface temperature domain.

While $\mathrm{X}$ and $\mathrm{L}$ were examined independently for this study, they ultimately combine to determine the fin count on the heater surface. Table 5 summarizes $\mathrm{A}_{\mathrm{s}}, \mathrm{CHF}$, and fin count (i.e pin fins $/ \mathrm{cm}^{2}$ ) for the degassed and gassy case for each parameter variation. However, since $A_{s}$ is coupled to the fin count via the pin fin area for the $\mathrm{X}$ and $\mathrm{L}$ variations, further examination is required for understanding of the heat transfer mechanisms impacting the heat flux enhancement.

\begin{tabular}{|c|c|c|c|c|c|}
\hline $\begin{array}{l}\mathrm{S} \\
\mathrm{T} \\
\mathrm{U} \\
\mathrm{D} \\
\mathrm{Y}\end{array}$ & $\begin{array}{l}\text { Pin Fin } \\
\text { Surface }\end{array}$ & $\begin{array}{c}A_{s} \\
\left(\mathrm{~cm}^{2}\right)\end{array}$ & $\begin{array}{l}\text { Degas. } \\
\text { q"'CHF } \\
\left(\mathrm{W} / \mathrm{cm}^{2}\right)\end{array}$ & $\begin{array}{l}\text { Gassy } \\
\text { q" } \mathrm{cHF}^{2} \\
\left(\mathrm{~W} / \mathrm{cm}^{2}\right)\end{array}$ & $\begin{array}{l}\text { Pin } \\
\text { Fins } \\
/ \mathrm{cm}^{2}\end{array}$ \\
\hline \multirow{3}{*}{$(X)$} & $1 \mathrm{c}$ & 4.0 & 117 & 145 & 25.0 \\
\hline & $2 c$ & 3.9 & 104 & 132 & 16.0 \\
\hline & $3 c$ & 3.8 & 103 & 132 & 11.0 \\
\hline \multirow{3}{*}{$(L)$} & $1 \mathrm{c}$ & 4.0 & 117 & 145 & 25.0 \\
\hline & $4 \mathrm{c}$ & 3.3 & 112 & 142 & 16.0 \\
\hline & $5 \mathrm{c}$ & 2.9 & 97 & 123 & 11.0 \\
\hline \multirow{3}{*}{$(\mathrm{H})$} & $1 \mathrm{c}$ & 4.0 & 117 & 145 & 25.0 \\
\hline & $6 c$ & 5.0 & 116 & 145 & 25.0 \\
\hline & $7 c$ & 6.0 & 118 & 146 & 25.0 \\
\hline
\end{tabular}

Table 5 Summary Correlation for Pin Structures and CHF

\section{SUMMARY AND CONCLUSIONS}

Spray cooling heat flux measurements were performed on cubic pin fin enhanced surfaces and one flat surface using PF5060. Tests were performed under nominally degassed (fluid at $41.4 \mathrm{kPa})$ and gassy $\left(\mathrm{N}_{2}\right.$ dissolved gas at $\left.100.7 \mathrm{kPa}\right)$ conditions. The volumetric flow rate $\left(0.01 \mathrm{~m}^{3} / \mathrm{m}^{2} \mathrm{~s}\right)$ and nozzle height from the surface $(17 \mathrm{~mm})$ were held constant for all the tests.

The maximum heat flux attained for both the nominally degassed and gassy cases $\left(121 \mathrm{~W} / \mathrm{cm}^{2}\right.$ and $149 \mathrm{~W} / \mathrm{cm}^{2}$ respectively) occurred for the surface structures with the maximum height and the minimum width and spacing.

In both the nominally degassed and the gassy cases, pin fin width and spacing had a large impact on heat transfer while the pin fin height had very little impact.

Decreasing the pin fin size and separation distance increases the heat flux for both the nominally degassed and gassy cases.

Heat flux for the enhanced surfaces did not scale with the total exposed surface area or the base area in neither the nominally degassed or gassy case studies.

\section{ACKNOWLEDGMENTS}

This research was supported by the Thermal Management group of the Laboratory for Physical Sciences and funded by the Laser Risk Reduction Program (LRRP) at the NASA Goddard Space Flight Center. Dr. Jungho Kim and Dr. Kenneth Kiger would like to acknowledge the generous support of the Office of Naval Research under contract number N000140410315 directed by Dr. Mark Spector. The authors would like to thank Dr. Paul Boudreaux, for his assistance, as well as J.B. Dotellis and Lester Lorentz for their support in machining the copper test articles and their surfaces. Special 
thanks is also given to Rick Fedorchak and Richard Freburger of NASA Goddard Space Flight Center for their test support as well as Parker Hannifin's Gas Turbine Fluid Systems Division (GTFSD) for supplying the spray nozzle.

\section{REFERENCES}

[1] Sehmbey, M., Chow, L., Pais, M., and Mahefkey, T., 1995, "High heat flux spray cooling of electronics," $12^{\text {th }}$ Symposium on Space Nuclear Power and propulsion, Albuquerque, NM, Jan., AIP Conference Proceedings no. 324, pp. 903-909

[2] Yang, J., Pais, M., and Chow, L., 1993, " Critical Heat Flux Limits In Secondary Gas Atomized Liquid Spray Cooling," Experimental Heat Transfer, Vol. 6, pp. 55-67

[3] Estes, K.A., and Mudawar, I., 1995, " Correlation of Sauter mean diameter and critical heat flux for spray cooling of small surfaces," International Journal of Heat and Mass Transfer, Vol.38, No.16, pp. 2985-2996

[4] Yang, J., Chow, L., and Pais, M., 1996, "Nucleate Boiling Heat Transfer in Spray Cooling," Journal of Heat Transfer, Vol. 118, pp. 668-671

[5] Chen, R-H., Chow, L., and Navedo, J., 2002, "Effects of spray characteristics on critical heat flux in subcooled water spray cooling," International Journal of Heat and Mass Transfer, Vol. 45, pp. 4033-4043

[6] Sehmbey, M., Pais, M., and Chow, L., 1992, "A study of diamond laminated surfaces in evaporative spray cooling," Thin Solid Films, Vol. 212, pp. 25-29

[7] Healy, W., Halvorson, P., Hartley, J., and Abdel-Khalik, S., 1998, "A critical heat flux correlation for droplet impact cooling at low Weber numbers and various ambient pressures," International Journal of Heat and Mass Transfer, Vol. 41, pp. 975-978

[8] Sawyer, M., Jeter, S., and Abdel-Khalik, S., 1997, " A critical heat flux correlation for droplet impact cooling," International Journal of Heat Transfer, Vol. 40, No. 9, pp. 2123-2131

[9] Bernadin, J.D., and Mudawar, I., 1999, "The Leidenfrost Point: Experimental Study and Asessment of Existing Models," Journal of Heat Transfer, Vol. 121, pp. 894-903

[10] Pais, M., Chow, L., and Mahefkey, E., 1992, "Surface Roughness and Its Effects on the Heat Transfer Mechanism of Spray Cooling," Journal of Heat Transfer, Vol. 114, No. 1, pp. 211-219
[11] Mudawar, I., and Estes, K., 1996, "Optimizing and Predicting CHF in Spray Cooling of a square surface," Journal of Heat Transfer, Vol. 118, pp. 672-679

[12] Qiao, Y.M., and Chandra, S., 1997, " Experiments on adding a surfactant to water drops boiling on a hot surface," Proceedings of the Royal Society of London, Vol. 453, pp. 673689

[13] Qiao, Y., and Chandra, S., 1998, "Spray Cooling Enhancement by Addition of a Surfactant," Journal of Heat Transfer, Vol. 120, pp. 92-98

[14] Mesler, R., 1993, "Surface Roughness and It's Effects on the Heat Transfer Mechanism of Spray Cooling," Journal of Heat Transfer, Vol. 115, pp. 1083-1085

[15] Rini, D., Chen, R.-H., Chow, L., 2002, "Bubble Behavior and Nucleate Boiling Heat Transfer in Saturated FC-72 Spray Cooling," Journal of Heat Transfer, Vol. 124, pp. 63-72

[16] Silk, E.A., Kim, J., and Kiger, K., 2004, “ Investigation of Enhanced Surface Spray Cooling," ASME International Mechanical Engineering Congress, Anaheim, CA, Nov.13-19, IMECE2004 Conference Proceedings

[17] Honda, H., Takamastu, H., and Wei, J.J., 2002, “ Enhanced Boiling of FC-72 on Silicon Chips With Micro-Pin-Fins and Submicron-Scale Roughness," Journal of Heat Transfer, Vol. 124, pp. 383-390

[18] Chien, L.H., and Webb, R.L., 1998a, "A Parametric Study of Nucleate Boiling on Structured Surfaces, Part I: Effect of Tunnel Dimensions," Journal of Heat Transfer, Vol. 120, pp. 1042-1048

List of Figures:

Fig. 1. Spray Cooling Test Rig Configuration

Fig. 2. Copper block schematic with TC locations

Fig. 3. Spray Uniformity Test Schematic

Fig. 4. Enhanced Surfaces Geometry Schematic

Fig. 5. Enhanced Surface CCD Images

Fig. 6. Heat Flux as a function of Surface Temperature using variable structure size $(\mathrm{X})$ for degassed case

Fig. 7. Heat Flux as a function of Surface Temperature using variable structure separation distance (L) for degassed case

Fig. 8. Heat Flux as a function of Surface Temperature using variable structure height $(\mathrm{H})$ for degassed case

Fig. 9. Heat Flux as a function of Surface Temperature using variable structure size $(\mathrm{X})$ for gassy case

Fig. 10. Heat Flux as a function of Surface Temperature using variable structure separation distance (L) for gassy case Fig. 11. Heat Flux as a function of Surface Temperature using variable structure height $(\mathrm{H})$ for gassy case 